Article

\title{
Fine Root Biomass and Its Relationship with Aboveground Traits of Larix gmelinii Trees in Northeastern China
}

\author{
Shengwang Meng ${ }^{1}$ (D), Quanquan Jia ${ }^{2}$, Guang Zhou ${ }^{1}$, Hua Zhou ${ }^{1}$, Qijing Liu ${ }^{1, *}$ and Jian Yu ${ }^{1}$ \\ 1 College of Forestry, Beijing Forestry University, Beijing 100083, China; wangzai1220@126.com (S.M.); \\ zhouguang910313@163.com (G.Z.); jeamourvous@163.com (H.Z.); yujian1986829@sina.com (J.Y.) \\ 2 Jiangxi Academy of Forestry, Nanchang 330032, China; auu2132057@163.com \\ * Correspondence: liuqijing@bjfu.edu.cn; Tel.: +010-6233-8133
}

Received: 23 November 2017; Accepted: 12 January 2018; Published: 16 January 2018

\begin{abstract}
Fine roots play a prominent role in forest carbon flux, nutrient and water acquisition; however, information on fine roots remains scarce due to the limitation of measuring methods. In this study, a nested regression method was used to estimate the biomass and surface area of fine roots of individual Larix gmelinii trees that dominate northernmost China. Aboveground traits including leaf biomass, leaf area, stem volume and aboveground biomass were also investigated. In particular, the relationships between leaves and fine roots, in terms of biomass and area, were examined. The results revealed that allometric models of fine roots, total roots, and leaves consistently fit well with Adj. $R^{2}=0.92-0.97$. The root-shoot ratio at the individual tree level was approximately 0.28. There were robust positive linear correlations between absorption (fine root biomass, fine root surface area) and production (leaf biomass, leaf area) (Adj. $R^{2}=0.95, p<0.001$ ). In conclusion, the close coupling between fine roots and leaves presented in this study provides support for the theory of functional equilibrium.
\end{abstract}

Keywords: fine root; leaf; biomass; relationship; Larix gmelinii

\section{Introduction}

Boreal forests play a critical role with respect to their contribution to global carbon dynamics [1]. Mid- and high-latitude forests contain approximately $63 \%$ of the total carbon pool contained in global forest vegetation, and soils contain more than $66 \%$ of the carbon in forest ecosystems [2]. To better understand the balance between carbon sequestration and emission in boreal biomes, more information on matter cycling is needed. However, accurate determination of carbon sequestration in forest ecosystems has been limited by the difficulty of finding an appropriate method to acquire a credible estimate of the production and turnover rate of fine roots [3].

Fine roots (diameter $\leq 2 \mathrm{~mm}$ ) may only represent a small amount of the total forest biomass [4,5]. However, due to their short lifespan and rapid turnover rate, the production of fine roots accounts for approximately $33 \sim 60 \%$ of annual net primary production (NPP) in forest ecosystems [6-8]. Accurate estimation of fine root biomass and comprehensively understanding their dynamics are therefore crucial for evaluating carbon and nutrient budgets of the whole terrestrial ecosystem [7].

It is well known that fine roots perform a variety of functions: link every component of the forest ecosystem, have strong relevance for inorganic matter assimilation [9], function as a major source of organic matter in the soil $[10,11]$, and last but not least, fine roots are responsible for water and nutrient uptake. In contrast, leaves play an important role in energy and carbon capture. Leaves produce carbohydrates through photosynthesis [8], and the production drives root activity [11]. This indicates that fine roots and leaves are dependent on each other, namely, an intrinsic linkage exists between 
them, which is the prediction of the functional equilibrium theory [12]. This theory has been widely used for describing fine root growth patterns by studying the ratio of root to leaf biomass $[13,14]$. Close relationships between fine root biomass (or surface area) and leaf biomass (or area) have been found in saplings or young trees [15], but supporting evidence from adult or larger trees is extremely scarce due to the difficulty of observing and measuring reliable fine root biomass and surface area [16].

The high heterogeneity of distribution of fine roots in the soil matrix $[13,17]$ makes it difficult to obtain their biomass accurately and quickly. At present, no universal and robust standard methods for biomass estimation exist in the field of root studies [10]. Direct excavation is simple and especially suitable for quantifying fine roots at the individual level but is highly time-consuming and labor-intensive. Furthermore, the damaging effects are significant. Minirhizotron tubes with a camera connected to image analysis software is one of the best methods to record the growth process and to investigate root heterogeneity at very small scales $[18,19]$. However, this technique requires the simultaneous collection of root cores that need to be separated and processed to establish models to convert diameter and length into biomass [3]. In addition, minirhizotron tubes are costly, and careful consideration should be given when installing them since they influence root growth patterns and soil microenvironments. The ingrowth core method is typically applied to estimate fine root productivity at the stand and forest ecosystem level, especially in tropical forest ecosystems with fast-growing roots [20]. However, this approach has the disadvantage that chemical and physical properties of the soil may be changed, leading to a certain degree of impact on root growth [21].

Thus, regression models seem to be an effective approach for estimating root biomass with easy-to-measure metrics as predictor variables [22,23]. Diameter at breast height $(d b h)$ is a very reliable and easy-to-measure variable in field surveys, and models using $d b h$ as the sole predictor for predicting biomass perform the best, while tree height $(h)$ is considered as a less important factor [24]. Nevertheless, due to technical limits in data collection, previous studies provide very little insight into fine root biomass models of individual trees [25], and a gap remains in the root-leaf relationship, especially for larger trees.

Essential improvement and standardization of methods for accurately and efficiently studying root systems are critically needed. Accordingly, a nested regression method [26] proposed for establishing branch biomass models was applied in this study by assuming that branching patterns of roots are similar to those of branches [27]. The biomass of root branches is obtained by adding all root sub-branches protruding from them. Specifically, each root sub-branch is regarded as an independent sample, which is analogous to its parent root branch. Biomass models were stepwise developed in the sequence of single main root branches (defined as root axes), root branches, and individual trees. Thus, fine root and total root biomass can be easily measured. Since data are nested rather than independent, the number of measured samples could be minimized, making the approach time- and cost-effective.

Larix gmelinii is the most abundant tree species predominating in the northeastern forest area of China and plays a critical role in timber production, carbon flux, biodiversity protection and recovery. However, few studies on fine roots have been conducted in natural L. gmelinii forests [28]. Quantification of fine root production is urgently needed for robust understanding and estimation of the carbon and nutrient cycling of forest systems. The specific objectives of the present study were to develop allometric models for aboveground and belowground traits regressed against $d b h$ by taking advantage of nested regression, to examine whether aboveground biomass and stem volume are good predictors of fine root biomass and fine root surface area, and in particular, to test the correlation between fine root and leaf biomass and area.

\section{Materials and Methods}

\subsection{Study Site}

The study was conducted in June 2013 in a natural L. gmelinii forest in the Daxing' anling mountains of the Inner Mongolia autonomous region $\left(47^{\circ} 3^{\prime} 40^{\prime \prime}-53^{\circ} 20^{\prime} 35^{\prime \prime} \mathrm{N}, 119^{\circ} 36^{\prime} 20^{\prime \prime}-125^{\circ} 19^{\prime} 50^{\prime \prime} \mathrm{E}\right.$ ), which is 
near the border with Russia. This area is associated with a distinct cold temperate continental monsoon climate; the mean annual precipitation is $450-550 \mathrm{~mm}$, and the mean annual temperature is $-5.8^{\circ} \mathrm{C}$, with extreme maximum and minimum temperatures of $40^{\circ} \mathrm{C}$ and $-52{ }^{\circ} \mathrm{C}$, respectively. The total area of the Daxing' anling region is $106,575 \mathrm{~km}^{2}$ and the total forestland area is $83,179 \mathrm{~km}^{2}$. The elevation ranges from 425 to $1760 \mathrm{~m}$ above sea level with flat to undulating terrain. The predominant substrate is dark coniferous forest soil, corresponding to umbrepts in USA soil taxonomy system. The overstory species composition is dominated by L. gmelinii, Betula dahurica and Populus davidiana, with approximately 93\% cover area of the total forestland. Understory shrubs mainly include Rhododendron parvifolium, Ledum palustre and Rhododendron dauricum, among others.

\subsection{Measurement and Data Collection}

To quantify the biomass of specific components, destructive sampling was applied. A total of 17 L. gmelinii trees ranging in size from 5 to $41 \mathrm{~cm} d b h$ were felled and excavated at one site with a stand density of 1177 trees per ha and mean $d b h$ of $19.3 \mathrm{~cm}$. Understory plants included Ledum palustre, Betula fruticosa Pall, and herbage.

Each sampled tree was divided into the following components: roots, stem, branches, and leaves. For determination of belowground biomass, the nested regression method was applied [26,27]. Roots protruding from the stump were defined as first order, and those branching from the first order as second order (Figure 1), and the same manner for the rest. Final-order root and root branches, removing all lateral roots, were referred to as the single main root branch, namely, the root axis (Figure 1). As such, a root branch is composed of a series of root axes of all orders. Accordingly, the root axis was treated as a full cone-like minor tree bole for volume calculation. To facilitate measurement and ensure accuracy, root axes with a diameter larger than $2 \mathrm{~mm}$ were sectioned into segments of $30 \mathrm{~cm}$ in length, otherwise the segment was $10 \mathrm{~mm}$. Diameters at both ends of a section were measured. Equations (1) and (2) were used for calculating the volume $(V)$ and surface area $(S)$ of root axes, respectively,

$$
\begin{gathered}
V=\frac{\pi}{4}\left[\frac{1}{2}\left(d_{0}^{2}+d_{n}^{2}\right)+\sum_{i=1}^{n-1} d_{i}^{2}\right] l+\frac{\pi}{12} d_{n}^{2} l^{\prime} \\
S=\frac{1}{2}\left[d_{0}+d_{n}+2 \sum_{i=1}^{n-1} d_{i}\right] \pi l+\frac{1}{2} \pi d_{n} l^{\prime}
\end{gathered}
$$

where $d_{0}$ and $d_{n}$ are the basal diameters of the root branch and the top section, respectively, $d_{i}$ is the mid-diameter of a section, $l$ and $l^{\prime}$ are the section length and length of the top section, respectively.

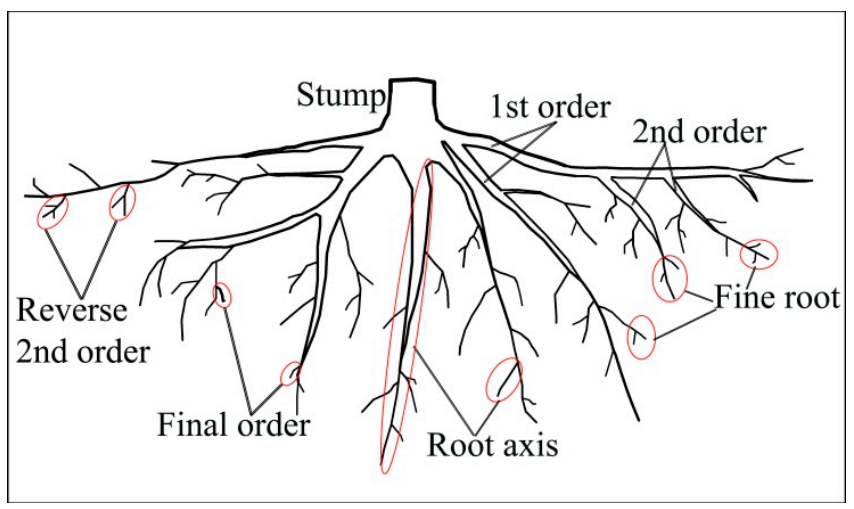

Figure 1. Diagram showing the root classification and the definition of a root axis. Segments with a diameter less than $2 \mathrm{~mm}$ on the tip of larger roots are also fine roots. 
The first step in excavation was to clear the topsoil around the root collar so as to expose all first-order roots. Root diameters at the base, where they protrude from the stump, were recorded with a digital caliper $( \pm 0.01 \mathrm{~mm})$. According to diameter classes, we selected the first-order roots and recorded their second-order root diameters. Then, based on diameter classes of the second-order roots, samples were chosen for measuring all diameters of the third order. In the same way, all sub-order root branches of sampled root branches were measured. Thus, we obtained a detailed branching pattern of the root system. To be specific, the final order (up to a maximum of 12th order) is also defined as a reverse first order. Fine roots were sealed in plastic bags before being taken back to the laboratory to prevent loss of moisture. We defined roots $\leq 2 \mathrm{~mm}$ in diameter as fine roots and separated them manually and carefully in a culture dish with the help of forceps. The diameter and length of fine roots were measured under a $40 \times$ stereomicroscope with an ocular micrometer $( \pm 0.025 \mathrm{~mm})$.

It is difficult to acquire intact fine roots without any breakage or loss due to obstacles such as hard rocks. In such cases, the diameters at the breaking points of the unexcavated roots were recorded. A grafting method was used to match broken roots with one or more separate root segments that had the same diameter as that of the breaking points.

Likewise, leaf and branch biomass data were collected by the same method as well. Needles attached to a single main branch (defined as a branch axis) were counted in each fascicle. Three hundred fascicles were randomly pooled in the field and stored in sealed plastic bags. The number of needles per fascicle was determined upon arrival in the laboratory before scanning at 1200 dpi resolution. The scanned images were subsequently analyzed in Adobe Photoshop 7.0 to obtain average individual leaf area. Then, the dry mass of small petioles and needles was determined by oven-drying at $105^{\circ} \mathrm{C}$ for $72 \mathrm{~h}$.

The tree trunk was sectioned into 2-m intervals; the top section with a length less than $2 \mathrm{~m}$ was treated as the treetop. The sectional volume was calculated by an approximate formula, i.e., Equation (1).

Sub-samples of stem, branch, and root (including fine root) were harvested and transferred to the laboratory for investigating tissue density, expressed as specific gravity. Water displacement was adopted for volume measurement before oven drying at $105^{\circ} \mathrm{C}$ to a constant weight. The ratio of dry weight to fresh volume for individual sub-samples, namely, basic density, was used to convert volume to biomass $[29,30]$. Table 1 presents these descriptive statistics for general variables.

Table 1. Descriptive statistics of sub-samples and sampled trees for developing biomass equations.

\begin{tabular}{cccccc}
\hline Variable & Definition & Min & Max & Mean & S.D. \\
\hline- & Basic density of branch $\left(\mathrm{g} / \mathrm{cm}^{3}\right)$ & 0.40 & 0.52 & 0.46 & 0.05 \\
- & Basic density of stem wood $\left(\mathrm{g} / \mathrm{cm}^{3}\right)$ & 0.39 & 0.51 & 0.50 & 0.03 \\
- & Basic density of stem bark $\left(\mathrm{g} / \mathrm{cm}^{3}\right)$ & 0.35 & 0.39 & 0.37 & 0.01 \\
- & Number of needles per leaf fascicle & 22 & 28 & 26 & 3 \\
- & Leaf fascicle mass $(\mathrm{g})$ & 0.016 & 0.024 & 0.021 & 0.0027 \\
- & Needle area $\left(\mathrm{cm}^{2}\right)$ & 0.066 & 0.18 & 0.13 & 0.032 \\
- & Short shoot mass $(\mathrm{g})$ & 0.0035 & 0.0075 & 0.0060 & 0.0021 \\
$M_{\mathrm{tr}}$ & Total root biomass per tree $(\mathrm{kg})$ & 1.51 & 222.52 & 51.25 & 67.51 \\
$M_{\mathrm{fr}}$ & Fine root biomass per tree $(\mathrm{kg})$ & 0.46 & 14.86 & 4.38 & 4.66 \\
$S_{\mathrm{fr}}$ & Fine root surface area per tree $\left(\mathrm{m}^{2}\right)$ & 4.51 & 160.71 & 46.96 & 50.66 \\
$M_{1}$ & Leaf biomass per tree $(\mathrm{kg})$ & 1.17 & 61.77 & 17.02 & 19.22 \\
$S_{1}$ & Leaf area per tree $\left(\mathrm{m}^{2}\right)$ & 15.70 & 827.48 & 227.92 & 257.58 \\
$M_{\mathrm{a}}$ & Aboveground biomass per tree $(\mathrm{kg})$ & 5.33 & 824.17 & 181.59 & 224.13 \\
$V$ & Stem volume per tree $\left(\mathrm{m}^{3}\right)$ & 0.0078 & 1.36 & 0.30 & 0.36 \\
\hline
\end{tabular}

\subsection{Step-Fitting Model and Statistical Analyses}

The root axes were treated as basic units for whole root biomass estimation, and 940 such root axes were collected. Their volumes were calculated through the sectional method as described above. Since a wide range of root volume and surface area was observed, piecewise power equations were applied for establishing volume and surface area models of roots in order to ensure the predictive 
accuracy. Firstly, all data were visually divided into subsets according to the basic diagnostic scatter plots of root axes biomass and surface area against diameter. Every two neighboring subsets had several overlapping data points. Then, we fitted separate equations to the subset data and found the intersection points among these equations by graphing them together. The intersection points are break points of the piecewise equations (Table 2).

Table 2. Summary of parameters and prediction statistics for biomass and surface area of first-order root branches related to basal diameter. The power function of $y=a x^{b}$ was applied for all equations, where $y$ represents biomass $(\mathrm{mg})$ or surface area $\left(\mathrm{mm}^{2}\right), x$ represents root diameter $(\mathrm{mm}), a$ and $b$ are coefficients. All models had the basal diameter of the first-order root branch as the independent variable. Root branch biomass with a diameter less than $1.99 \mathrm{~mm}$ was calculated by the fine root biomass model. RMSE: Root mean squared error.

\begin{tabular}{|c|c|c|c|c|c|c|c|}
\hline Component & Application Range (mm) & $a$ & $b$ & RMSE & Adj. $R^{2}$ & $n$ & $p$ Value \\
\hline Root branch biomass & $1.99 \leq x \leq 240$ & 337.17 & 1.99 & $1.24 \mathrm{~kg}$ & 0.99 & 270 & $<0.001$ \\
\hline \multirow[t]{3}{*}{ Fine root biomass } & $0<\bar{x}<\overline{0} .34$ & 2835.45 & 6.95 & $0.83 \mathrm{mg}$ & 0.92 & 619 & $<0.001$ \\
\hline & $0.34 \leq x \leq 2.14$ & 95.38 & 3.83 & $0.20 \mathrm{~g}$ & 0.97 & 568 & $<0.001$ \\
\hline & $2.14 \leq x \leq 240$ & 599.10 & 1.42 & $85.44 \mathrm{~g}$ & 0.99 & 270 & $<0.001$ \\
\hline \multirow[t]{4}{*}{ Fine root surface area } & $0<\bar{x}<\overline{0.34}$ & $89,242.00$ & 6.59 & $34.82 \mathrm{~mm}^{2}$ & 0.88 & 619 & $<0.001$ \\
\hline & $0.34 \leq x \leq 1.01$ & 1944.70 & 3.07 & $1.84 \mathrm{~cm}^{2}$ & 0.87 & 338 & $<0.001$ \\
\hline & $1.01<x \leq 5.48$ & 1970.50 & 2.05 & $0.02 \mathrm{~m}^{2}$ & 0.94 & 352 & $<0.001$ \\
\hline & $5.48<x \leq 240$ & 5342.30 & 1.46 & $1.04 \mathrm{~m}^{2}$ & 0.99 & 148 & $<0.001$ \\
\hline
\end{tabular}

Based on the detailed branching of the root system investigated in the field, volume was progressively calculated in the reverse sequence. The reverse second-order root branch volume was acquired by summing the volumes of the reverse second-order root axis and its side roots, i.e., the reverse first-order root branches. A regression equation was established with these reverse second-order root branches volume data. Similarly, the reverse third-order root branch volume was calculated by summing the volume of the reverse third-order root axis and its side roots, which was calculated by the model fitted above. In this way, the range of independent variable was gradually extended until the reverse final order (namely the first order). Although the final model was developed based on root branch order, it was suitable for all diameters in the available range without considering the branching order. The entire root volume was calculated for each tree sample by using the appropriate root branch-level models for each root branch.

The same calculation method was applied for fine root volume, including independent fine root branches and the segments on the tip of larger roots (Figure 1) coinciding with fine root definition standard. In addition, the total root volume and leaf quantity were obtained by the nested regression method as well. Through one-way ANOVA, we found that the root moisture content showed no significant difference among diameter classes. The density data of coarse and fine roots were therefore pooled together to obtain a mean value of $0.44 \mathrm{~g} \cdot \mathrm{cm}^{-3}$, and this was simply multiplied by the root volume models to generate the root biomass models. Leaf biomass and leaf area models were derived by multiplying leaf quantity by average mass and average area, respectively. Finally, a standard form for allometric models (a power function) was fitted to the biomass and area data for root and leaf at the individual tree level.

All model fitting was evaluated by the root mean square error (Equation (3)) and adjusted coefficient of determination (Equation (4)). In order to test the reliability and precision of the nested regression method, we collected 18 first-order root branches and acquired their dry weight to make a comparison with the predicted values of the root branch model.

$$
\text { RMSE }=\sqrt{\frac{\sum_{i=1}^{n}\left(y_{i}-\hat{y}_{i}\right)^{2}}{n-k}}
$$




$$
\text { Adj. } R^{2}=1-\left(1-\frac{\sum_{i=1}^{n}\left(y_{i}-\hat{y}_{i}\right)^{2}}{\sum_{i=1}^{n}\left(y_{i}-\bar{y}\right)^{2}}\right) \frac{n-1}{n-k}
$$

where $y_{i}$ is the observed value, $\hat{y}_{i}$ is the predicted value, $\bar{y}$ is the mean value of the observed dataset, $n$ is the total number of data for model fitting and $k$ represents the number of parameters included in the model.

A total of 803 plots for operation design survey, covering various stand ages, stand conditions and stand densities, with mean $d b h$ of $10.9 \mathrm{~cm}$ and stand density of 1238 trees ha $^{-1}$, was compiled from local forest management enterprises for evaluating biomass at the plot level.

\section{Results}

\subsection{Root Branch Biomass and Surface Area Allometrics}

Piecewise power functions were fitted to the first-order root branch biomass, fine root biomass and surface area. The model parameters and statistics are displayed in Table 2. All of these models were statistically significant $(p<0.001)$, and the models performed well, with Adj. $R^{2}$ values ranging from 0.87 to 0.99 . Based on these developed models (Table 2), individual tree root biomass, fine root biomass and surface area can thus be estimated.

\subsection{Validation of Root Branch Biomass Model}

Because measuring fine root biomass in the field is difficult and impractical, the reliability of the nested regression method in biomass measurement and calculation was assessed by validating the root branch biomass model through a validation dataset. As displayed in Figure 2, the linear regression analysis showed that estimated and measured values were highly correlated, with Adj. $R^{2}=0.97$. In addition, a paired samples $t$-test under the significance level of 0.05 suggested that there was no significant difference between simulated and observed values $(p=0.15)$.

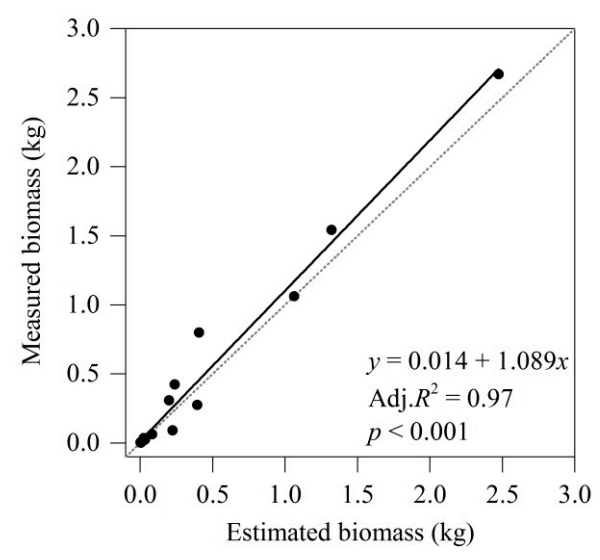

Figure 2. Scatterplot of the estimated ( $x$-axis) and the measured ( $y$-axis) values for the first-order root branch $(n=18)$. The dashed line indicates 1:1 equivalence. Linear regression and associated Adj. $R^{2}$ are shown.

\subsection{Individual-Tree Biomass and Surface Area Allometrics}

Power functions were fitted to the biomass and area data for leaf and root. Table 3 provides estimated values of the model coefficient and fitting statistics. Clearly, $d b h$ was significantly correlated with biomass and surface area of roots and leaves. In other words, $d b h$ is an excellent predictor. All models of different components were highly significant $(p<0.001)$ in correlation with Adj. $R^{2}$ values ranging from 0.92 to 0.97 . The pattern of biomass allocation to the belowground and aboveground 
components showed that the root-shoot ratio at the individual tree level was approximately 0.28 with a standard deviation of 0.10 .

Table 3. Model parameters and performance criteria of biomass and surface area $(n=17)$.

\begin{tabular}{cccc}
\hline Model & RMSE & Adj. $\boldsymbol{R}^{\mathbf{2}}$ & $\boldsymbol{p}$ Value \\
\hline$M_{\mathrm{tr}}=0.056 d b h^{2.230}$ & $16.47 \mathrm{~kg}$ & 0.94 & $<0.001$ \\
$M_{\mathrm{fr}}=0.016 d b h^{1.866}$ & $0.92 \mathrm{~kg}$ & 0.97 & $<0.001$ \\
$S_{\mathrm{fr}}=0.155 d b h^{1.890}$ & $9.75 \mathrm{~m}^{2}$ & 0.92 & $<0.001$ \\
$M_{1}=0.057 d b h^{1.876}$ & $5.76 \mathrm{~kg}$ & 0.96 & $<0.001$ \\
$S_{1}=0.757 d b h^{1.877}$ & $77.56 \mathrm{~m}^{2}$ & 0.96 & $<0.001$ \\
\hline
\end{tabular}

The total biomass density and root biomass density of our plots were $70.97 \mathrm{t} \cdot \mathrm{ha}^{-1}$ and $15.70 \mathrm{t} \cdot \mathrm{ha}^{-1}$, respectively, indicating a root-shoot ratio of 0.28 in these stands, which is numerically equal to that for individual trees. Fine root biomass was $1.69 \mathrm{t} \cdot \mathrm{ha}^{-1}$, which accounted for $10.8 \%$ of total root biomass and had a ratio of 0.03 relative to aboveground biomass. In addition, leaf biomass density was $5.81 \mathrm{t} \cdot \mathrm{ha}^{-1}$, approximately 3 times higher than that of fine roots.

\subsection{Fine Root and Aboveground Relationships}

There were highly significant $(p<0.001)$ positive linear correlations between biomass and surface area of fine roots and those of leaves for individual trees, with Adj. $R^{2}=0.94$ for both equations (Figure 3). In addition, strong positive linear relationships were observed between biomass and surface area of fine roots and aboveground production (biomass and stem volume) (Adj. $R^{2}$ ranging from 0.90 to 0.94 ). The linear regression between fine root biomass and aboveground biomass indicated that fine root biomass was approximately $2 \%$ of aboveground biomass.
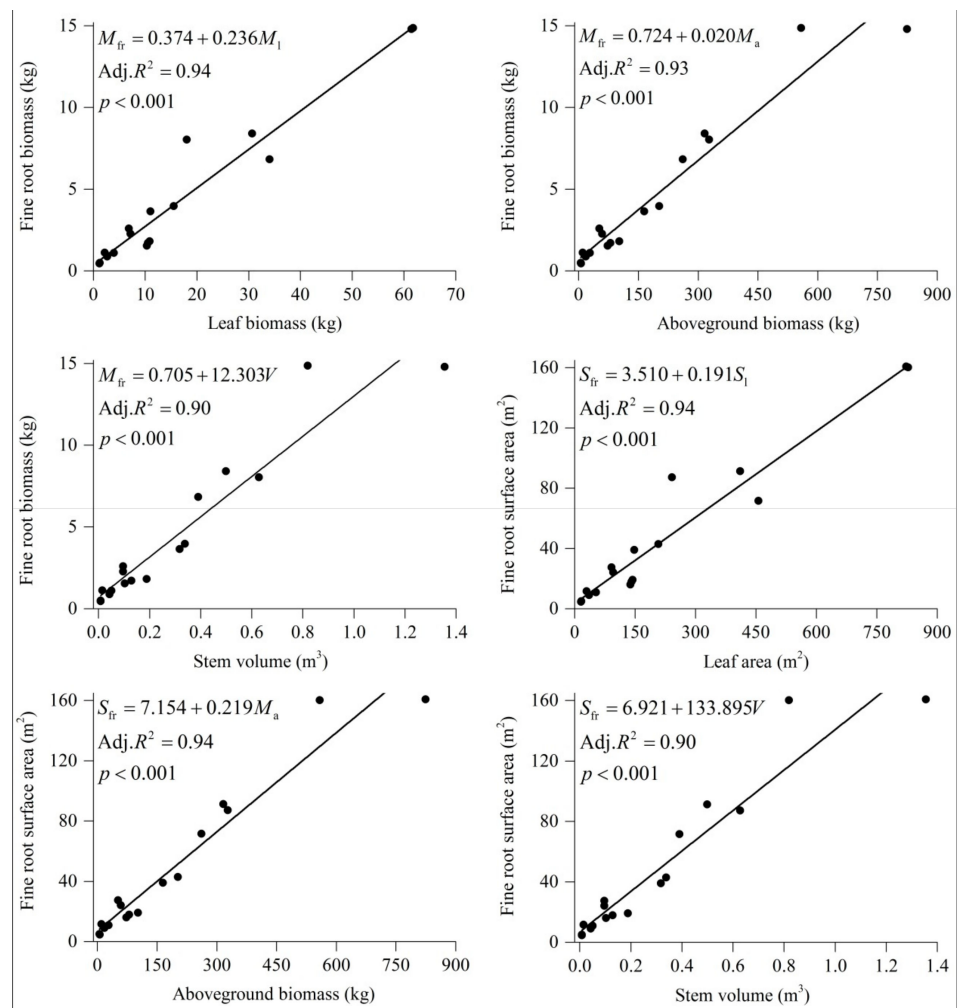

Figure 3. Parameter estimates and their adjusted $R^{2}$ values and $p$ values of regression relationships between fine root and aboveground traits at the individual tree level. 


\section{Discussion}

Quantification of fine root biomass is essential for forest belowground ecosystems due to the critical role in nutrient absorption and soil organic matter accumulation [31]. In this study, the total root biomass, fine root biomass, fine root area, leaf biomass and leaf area of individual L. gmelinii trees were estimated and related to $d b h$. In particular, the study has demonstrated strong relationships between production (leaf biomass, leaf area) and absorption (fine root biomass, fine root surface area).

As fine roots cannot usually be estimated on an individual tree basis [13], previous allometric studies for L. gmelinii trees appear to be restricted to the models regarding aboveground and coarse roots without considering fine roots [32,33]. The ability of these models to effectively evaluate carbon cycle has been further hindered since fine root dynamics have significant impacts on carbon flux [20].

The nested regression method has the advantage that the entire root (including fine root) biomass of individual tree can be efficiently acquired without tedious weighing operation, and workload can be minimized, especially when time or labor force is limited [26]. In addition, with this method, the exposure time of roots to the atmosphere is substantially reduced, ensuring the original moisture contents so as to obtain precise measurements. When recording coarse root diameters, we exposed only the points that needed to be measured rather than destructively cutting them from the sample tree. In this way, non-destructive sampling was achieved by imposing minimal disturbance on soil and trees.

The regression model of root axes is fundamental for the subsequent model building of branches with all orders progressively. Because of error propagation property, a small deviation in the root axis model can cause large errors in the final model. Namely, the credibility of the root axis model is crucial for further accurate root biomass model development. Therefore, the error should be minimized in order to guarantee the reliability of regression models.

In comparison with previous reports concerning relationships between fine roots and leaves carried out at the individual seedling scale [15] or at the stand scale [16], this study focusing on this issue was conducted at the individual adult tree scale. The relationships between fine roots and leaves in terms of biomass and area showed a close correlation, suggesting that there is a tight coupling characteristic between production and absorption. Thus, the result indicates that the theory of functional equilibrium is also applicable to adult trees, similar to that for seedlings [15,27]. Regression analysis yielded robust linear fitting results, indicating that leaf biomass and area as the optimum indicators, can explain approximately $95 \%$ of the variation in fine root biomass and surface area, respectively. The linear relationships also indicated that the ratio of the fine root surface area and leaf area remains constant, signifying stable patterns of demand and supply irrespective of trees size, in agreement with a previous study on seedlings [34]. Consequently, fine root biomass and surface area can be readily estimated by the regression models. In addition, the positive relationship between fine root biomass and leaf biomass may suggest the importance that a large leaf biomass can produce a high fine root biomass [16].

There were also similar significant relationships of fine root biomass to aboveground biomass and stem volume, suggesting a close coupling between absorption and tree growth [15]. Accordingly, estimating the biomass of fine roots and the entire root system using existing forest inventory data of aboveground stocks would be relatively simple.

The mean root-shoot ratio of our plots was 0.28 in the present study; however, for larch species growing in the permafrost region of Siberia, it ranges from 0.38 to 0.67 irrespective of fine roots [35], when incorporating fine roots it can reach 0.75 [36]. This strongly indicates that the species allocates more biomass to root in colder sites, namely, the root-shoot ratio increases latitudinally [37]. In addition, the root-shoot ratio is an important factor for estimating belowground biomass when biomass models are not available [38].

It is estimated that the fine root turnover rate is 0.78 year $^{-1}$ [39], and the annual turnover amount of fine roots for our plots can reach $1.32 \mathrm{t} \cdot \mathrm{ha}^{-1} \cdot \mathrm{year}^{-1}$. Annual NPP of the previous study [40] was estimated to be $2.01 \mathrm{t} \cdot \mathrm{ha}^{-1} \cdot \mathrm{year}^{-1}$, so up to $66 \%$ of that can be allocated to fine root turnover. Thus, 
fine roots play a critical role in carbon accumulation and cycling in forest ecosystems. The sizable contribution of fine roots to forest carbon budget suggests that fine root dynamics should be taken into account when estimating carbon flux [41].

Many studies have found that fine root biomass varied in relation to environmental factors, including geographical location, elevation, and climatic conditions [8,20,42]. These factors affect the availability of soil nutrients and water and the function of fine roots [43]. A larger fine root system relative to leaves is required to obtain nutrients and support growth when nutrient availability is low (low soil fertility or a short growing season), leading to a higher fine root/leaf ratio [44]. As a consequence, the robust linear relationship between biomass and surface area of fine root and aboveground traits in this study refer exclusively to the specific stand site in Daxing'anling mountains of Inner Mongolia. Further research is still required to demonstrate how the fine root surface area is related to leaf area, since the relationship is age-and growth site-dependent as proposed in some previous studies $[13,44,45]$.

\section{Conclusions}

With the help of the nested regression method, we examined the aboveground and belowground allometry of L. gmelinii and obtained significant allometric models, which are important for tree growth processes, especially with regard to the carbon cycle. We found robust and significant linear relationships between fine root and aboveground traits; thus, the latter could be appreciable predictors of fine root biomass and fine root surface area. In particular, the positive relationships between leaf and fine root in terms of biomass and area demonstrated an intrinsic linkage, supporting the theory of functional equilibrium.

Acknowledgments: We would like to thank all of the laboratory assistants who provided help with data collection. The local forestry bureau helped greatly with both logistics and personnel during fieldwork. This research was financially supported by the National Natural Science Foundation of China (31670436).

Author Contributions: Q.J. and Q.L. conceived and designed the experiments; S.M., Q.J., G.Z. and Q.L. performed the experiments; S.M., Q.J. and H.Z. analyzed the data; J.Y. contributed analysis tools; S.M. wrote the paper.

Conflicts of Interest: The authors declare no conflict of interest.

\section{References}

1. Pan, Y.; Birdsey, R.A.; Fang, J.; Houghton, R.; Kauppi, P.E.; Kurz, W.A.; Phillips, O.L.; Shvidenko, A.; Lewis, S.L.; Canadell, J.G. A large and persistent carbon sink in the world's forests. Science 2011, 333, 988-993. [CrossRef] [PubMed]

2. Dixon, R.K.; Solomon, A.M.; Brown, S.; Houghton, R.A.; Trexier, M.C.; Wisniewski, J. Carbon pools and flux of global forest ecosystems. Science 1994, 263, 185-190. [CrossRef] [PubMed]

3. Vogt, K.A.; Vogt, D.J;; Bloomfield, J. Analysis of some direct and indirect methods for estimating root biomass and production of forests at an ecosystem level. Plant. Soil 1998, 200, 71-89. [CrossRef]

4. Silver, W.L.; Thompson, A.W.; McGroddy, M.E.; Varner, R.K.; Dias, J.D.; Silva, H.; Crill, P.M.; Keller, M. Fine root dynamics and trace gas fluxes in two lowland tropical forest soils. Glob. Chang. Biol. 2005, 11, 290-306. [CrossRef]

5. Hertel, D.; Leuschner, C. A comparison of four different fine root production estimates with ecosystem carbon balance data in a fagus-quercus mixed forest. Plant. Soil 2002, 245, 335.

6. Brunner, I.; Godbold, D.L. Tree roots in a changing world. J. For. Res. 2007, 12, 78-82. [CrossRef]

7. Xiao, C.W.; Sang, W.G.; Wang, R.-Z. Fine root dynamics and turnover rate in an asia white birch forest of donglingshan mountain, china. For. Ecol. Manag. 2008, 255, 765-773.

8. Jackson, R.B.; Mooney, H.A.; Schulze, E.D. A global budget for fine root biomass, surface area, and nutrient contents. Proc. Natl. Acad. Sci. USA 1997, 94, 7362-7366. [CrossRef] [PubMed]

9. Yunusa, I.A.M.; Zolfaghar, S.; Zeppel, M.J.B.; Li, Z.; Palmer, A.R.; Eamus, D. Fine root biomass and its relationship to evapotranspiration in woody and grassy vegetation covers for ecological restoration of waste storage and mining landscapes. Ecosystems 2012, 15, 113-127. [CrossRef] 
10. Van Do, T.; Osawa, A.; Sato, T. Estimation of fine-root production using rates of diameter-dependent root mortality, decomposition and thickening in forests. Tree Physiol. 2016, 36, 513-523. [CrossRef] [PubMed]

11. Du, E.; Fang, J. Linking belowground and aboveground phenology in two boreal forests in northeast china. Oecologia 2014, 176, 883-892. [CrossRef] [PubMed]

12. Wilson, J.B. A review of evidence on the control of shoot: Root ratio, in relation to models. Ann. Bot. 1988, 61, 433-449. [CrossRef]

13. Vanninen, P.; Mäkelä, A. Fine root biomass of scots pine stands differing in age and soil fertility in southern finland. Tree Physiol. 1999, 19, 823-830. [CrossRef] [PubMed]

14. Cannell, M.G.; Dewar, R. Carbon allocation in trees: A review of concepts for modelling. Adv. Ecol. Res. 1994, 25, 59-104.

15. O'Grady, A.P.; Worledge, D.; Battaglia, M. Above- and below-ground relationships, with particular reference to fine roots, in a young eucalyptus globulus (labill.) stand in southern tasmania. Trees 2006, 20, 531-538. [CrossRef]

16. Johansson, T. Biomass production and allometric above- and below-ground relations for young birch stands planted at four spacings on abandoned farmland. Forestry 2007, 80, 41-52. [CrossRef]

17. Koteen, L.E.; Raz-Yaseef, N.; Baldocchi, D.D. Spatial heterogeneity of fine root biomass and soil carbon in a california oak savanna illuminates plant functional strategy across periods of high and low resource supply. Ecohydrology 2015, 8, 294-308. [CrossRef]

18. Wilson, S.D.; Kalamees, R. Below-ground opportunities in vegetation science. J. Veg. Sci. 2014, 25, 1117-1125. [CrossRef]

19. Mommer, L.; Weemstra, M. The role of roots in the resource economics spectrum. New Phytol. 2012, 195, 725. [CrossRef] [PubMed]

20. Vogt, K.A.; Vogt, D.J.; Palmiotto, P.A.; Boon, P.; O’Hara, J.; Asbjornsen, H. Review of root dynamics in forest ecosystems grouped by climate, climatic forest type and species. Plant. Soil 1996, 187, 159-219. [CrossRef]

21. Hendricks, J.J.; Hendrick, R.L.; Wilson, C.A.; Mitchell, R.J.; Pecot, S.D.; Guo, D. Assessing the patterns and controls of fine root dynamics: An empirical test and methodological review. J. Ecol. 2006, 94, 40-57. [CrossRef]

22. Komiyama, A.; Ong, J.E.; Poungparn, S. Allometry, biomass, and productivity of mangrove forests: A review. Aquat. Bot. 2008, 89, 128-137. [CrossRef]

23. Ouimet, R.; Camire, C.; Brazeau, M.; Moore, J.-D. Estimation of coarse root biomass and nutrient content for sugar maple, jack pine, and black spruce using stem diameter at breast height. Can. J. For. Res. 2008, 38, 92-100. [CrossRef]

24. McNicol, I.M.; Berry, N.J.; Bruun, T.B.; Hergoualc'h, K.; Mertz, O.; de Neergaard, A.; Ryan, C.M. Development of allometric models for above and belowground biomass in swidden cultivation fallows of northern laos. For. Ecol. Manag. 2015, 357, 104-116. [CrossRef]

25. Cole, T.G.; Ewel, J.J. Allometric equations for four valuable tropical tree species. For. Ecol. Manag. 2006, 229, 351-360. [CrossRef]

26. Liu, Q.J. Nested regression for establishing tree biomass equations. J. Plant. Ecol. 2009, 33, 331-337. (In Chinese)

27. Jia, Q.Q.; Liu, Q.J.; Li, J.Q. Individual-based fine root biomass and its functional relationship with leaf for Pinus tabuliformis in northern china. Eur. J. For. Res. 2015, 134, 705-714. [CrossRef]

28. Quan, X.; Wang, C.; Zhang, Q.; Wang, X.; Luo, Y.; Bond-Lamberty, B. Dynamics of fine roots in five chinese temperate forests. J. Plant. Res. 2010, 123, 497-507. [CrossRef] [PubMed]

29. Chen, A.; Li, R.; Wang, H.; He, B. Quantitative assessment of human appropriation of aboveground net primary production in china. Ecol. Model. 2015, 312, 54-60. [CrossRef]

30. Kajimoto, T. Aboveground net production and dry matter allocation of Pinus pumila forests in the kiso mountain range, central Japan. Ecol. Res. 1994, 9, 193-204. [CrossRef]

31. Jackson, R.B.; Canadell, J.; Ehleringer, J.R.; Mooney, H.A.; Sala, O.E.; Schulze, E.D. A global analysis of root distributions for terrestrial biomes. Oecologia 1996, 108, 389-411. [CrossRef] [PubMed]

32. Dong, L.; Zhang, L.; Li, F. A compatible system of biomass equations for three conifer species in northeast, china. For. Ecol. Manag. 2014, 329, 306-317. [CrossRef]

33. Zeng, W.S. Integrated individual tree biomass simultaneous equations for two larch species in northeastern and northern china. Scand. J. For. Res. 2015, 30, 594-604. [CrossRef] 
34. Tyree, M.T.; Velez, V.; Dalling, J.W. Growth dynamics of root and shoot hydraulic conductance in seedlings of five neotropical tree species: Scaling to show possible adaptation to differing light regimes. Oecologia 1998, 114, 293-298. [CrossRef] [PubMed]

35. Kajimoto, T.; Matsuura, Y.; Osawa, A.; Abaimov, A.P.; Zyryanova, O.A.; Isaev, A.P.; Yefremov, D.P.; Mori, S.; Koike, T. Size-mass allometry and biomass allocation of two larch species growing on the continuous permafrost region in siberia. For. Ecol. Manag. 2006, 222, 314-325. [CrossRef]

36. Kajimoto, T.; Matsuura, Y.; Sofronov, M.A.; Volokitina, A.V.; Mori, S.; Osawa, A.; Abaimov, A.P. Aboveand belowground biomass and primary productivity of a larix gmelinii stand near tura, central siberia. Tree Physiol. 1999, 19, 815-822. [CrossRef] [PubMed]

37. Jomura, M.; Wang, W.J;; Masyagina, O.V.; Homma, S.; Kanazawa, Y.; Zu, Y.G.; Koike, T. Carbon dynamics of larch plantations in northeastern China and Japan. In Permafrost Ecosystems; Springer: Dordrecht, The Netherlands, 2010.

38. Kachamba, D.J.; Eid, T.; Gobakken, T. Above- and belowground biomass models for trees in the miombo woodlands of malawi. Forests 2016, 7, 38. [CrossRef]

39. Cheng, Y. Timing and Depth-Related Patterns of Fine Root Biomass, Production and Turnover in Larix olgensis Henry Plantation. Master's Thesis, Northeast Forestry University, Harbin, China, 2004. (In Chinese)

40. Bao, C.; Bai, Y.; Qing, M.; Chen, G.; Zhang, Q.; Wang, L. Study on the Larix gmelinii natural forest biomass carbon storage. J. Inn. Mong. Agric. Univ. 2010, 31, 77-82. (In Chinese)

41. Wang, C.; Han, S.; Zhou, Y.; Zhang, J.; Zheng, X.; Dai, G.; Li, M.-H. Fine root growth and contribution to soil carbon in a mixed mature Pinus koraiensis forest. Plant. Soil 2016, 400, 275-284. [CrossRef]

42. Chen, W.; Zhang, Q.; Cihlar, J.; Bauhus, J.; Price, D.T. Estimating fine-root biomass and production of boreal and cool temperate forests using aboveground measurements: A new approach. Plant. Soil 2004, 265, 31-46. [CrossRef]

43. Finér, L.; Ohashi, M.; Noguchi, K.; Hirano, Y. Factors causing variation in fine root biomass in forest ecosystems. For. Ecol. Manag. 2011, 261, 265-277. [CrossRef]

44. Helmisaari, H.-S.; Derome, J.; Nöjd, P.; Kukkola, M. Fine root biomass in relation to site and stand characteristics in norway spruce and scots pine stands. Tree Physiol. 2007, 27, 1493-1504. [CrossRef] [PubMed]

45. Xiao, C.W.; Ceulemans, R. Allometric relationships for below- and aboveground biomass of young scots pines. For. Ecol. Manag. 2004, 203, 177-186. [CrossRef] 